\title{
Seaweed Based Bio Polymeric Film and Their Application: A Review on Hydrocolloid Polysaccharides
}

\author{
Israt Parveen \\ Institute of Radiation and Polymer Technology, Atomic Energy Research Establishment, Savar, Dhaka, Bangladesh \\ Department of Textile Engineering, Mawlana Bhashani Science and Technology University, Santosh, Tangail-1902, Bangladesh \\ Kazi M. Maraz \\ Institute of Radiation and Polymer Technology, Atomic Energy Research Establishment, Savar, Dhaka, Bangladesh \\ Md. Iqbal Mahmud \\ Department of Textile Engineering, Mawlana Bhashani Science and Technology University, Santosh, Tangail-1902, Bangladesh
}

Ruhul A. Khan*

Institute of Radiation and Polymer Technology, Atomic Energy Research Establishment, Savar, Dhaka, Bangladesh

\begin{abstract}
The objective of this paper is to discuss the potential of seaweed based polysaccharides as biopolymer in the formulation development and its allied applications. This review is an attempt to describe possible ways to produce environmental friendly bio packaging, bio textile, bio medicinal stuffs that can be at least slightly decomposed to smaller substances by the living organisms from marine algae. The main applications in food packaging and biomedicine are briefly mentioned followed by tentative applications in the domains of packaging, textile, paper and medical textiles which are described. This review also suggests new perspectives for future studies with these polymers.
\end{abstract}

Keywords: Seaweed; Bio polymer; Biodegradable film; Alginate; Agar; Carrageenan.

\section{(c) (1) CC BY: Creative Commons Attribution License 4.0}

\section{Introduction}

During the last decades, numerous novel compounds have been found from marine (also called the mother of origin of life) organisms as a potential source for the development of pharmaceuticals, food, packaging and textiles that can be applied to improve human wellness. Seaweed refers to several species of marine plants and algae which maybe macroscopic, multicellular that grows in the ocean as well as in rivers, lakes, and other water bodies [1]. Generally, seaweed is plant like organism mostly found in coastal areas. Since the mid-19th century, they are distinguished into four major groups based on pigmentation: Blue algae, Green algae (more than 1800 species), brown algae (about 2000 species) or red algae (over 7200 species) and none are known to be poisonous. Brown and red algae are almost absolutely marine, whereas green algae may common in freshwater (lakes, rivers) and in landdwelling situation (rocks, houses, wall and tree bark) [2].Chemical composition of seaweed includes: Water:8090\%,Mineral:7-38\%, Carbohydrates:50\%,Protein:3-15\%(brown algae),10-48\%(red \& green algae), Lipid:1-3\% [3, 4].They differ in many ultra-structural and biochemical features including fine structure, storage compounds, composition of cell walls, photosynthetic pigments, ultrastructure of mitosis, presence/absence of flagella, connections between adjacent cells. Having some outstanding characteristics, the versatile marine plants and algae have potential ability to be used for nutrition, biomedicine, bioremediation herbalism, filtration and industrial purposes. Since the early 20th century, however, these biopolymers began to be replaced by synthetic polymers due to their better performance and more reproducible properties, as compared to naturally derived materials $[5,6]$. From the last few years, for packaging purpose and for the treatments of humankind, seaweed has become very popular from laboratory to industrial scale [7]. Considering all those factors, sustainable use of seaweeds as biopolymer has now become crucial in this biodegradable era for the growing interest in natural polymers.

\section{Seaweed as Biodegradable Polymeric Film}

Seaweed as biodegradable polymers has been broadly utilized as a part of bio packaging, food and biomedical applications in terms of their known biocompatibility, bio absorbability and biodegradability and nontoxicity. These polymers can be degradable, either enzymatic association or without enzymatically. Commonly three seaweedderived hydrocolloids polysaccharides are available in nature that has diversified application as bio polymeric film such as alginate, agar and carrageenan. However, there are others seaweed hydrocolloids polysaccharides, which are less significant like mannitol, fucoidan and funoran [8]. 


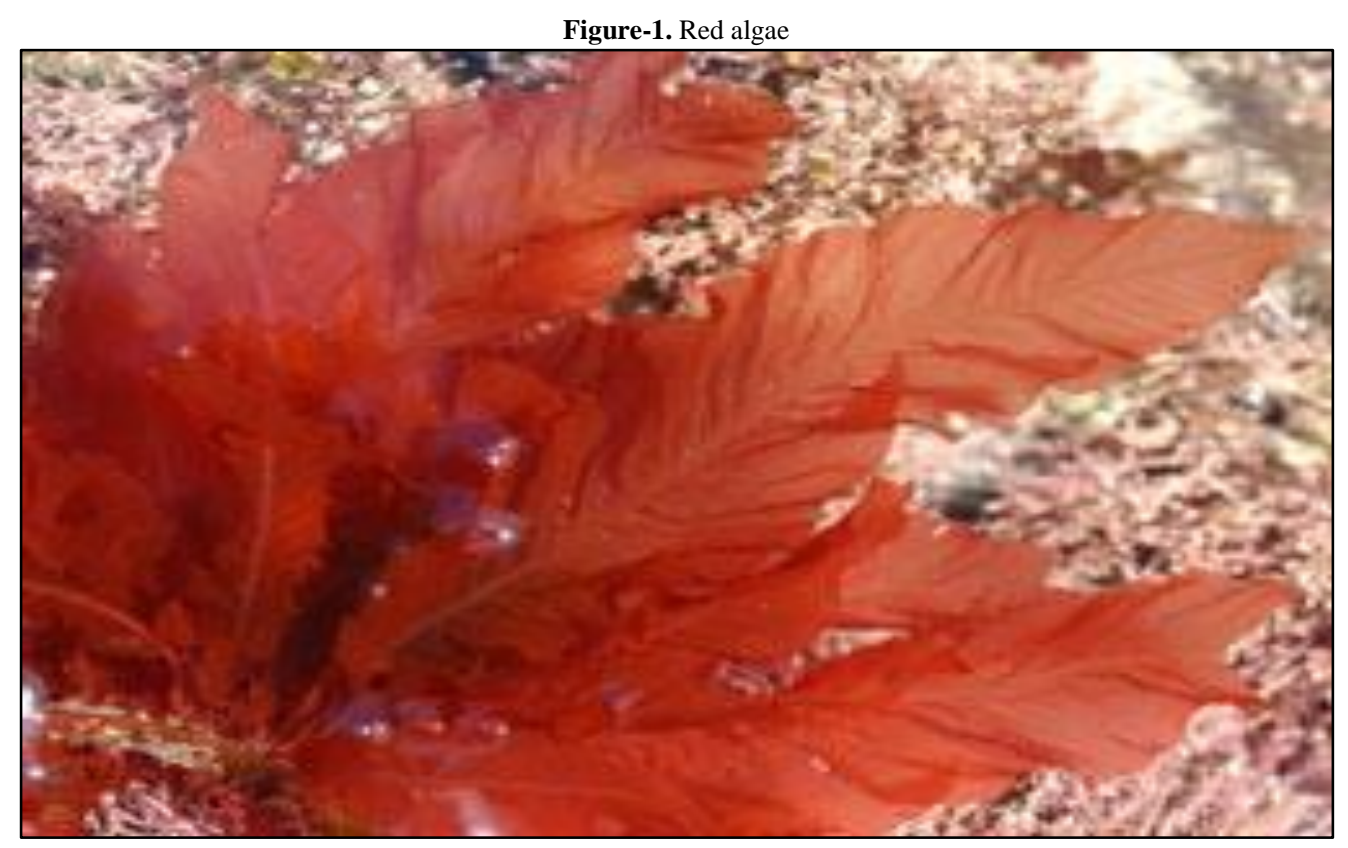

Red algae Kappaphycus and Betaphycus are the important sources of carrageenan. Gracilaria \& Gelidium can create gelatin like substances primarily known as agar. Over 7,000 species of red algae, only about 200 live in fresh water .Cell wall of red algae is extracted with water under neutral or alkaline conditions at elevated temperature. Carrageenan is completely biodegradable and has strong binding, gelling and hydrocolloid ability to form polymeric film. They are commonly used ingredient in food, growth medium for microorganisms, smart packaging and for biotechnological applications [8,9].

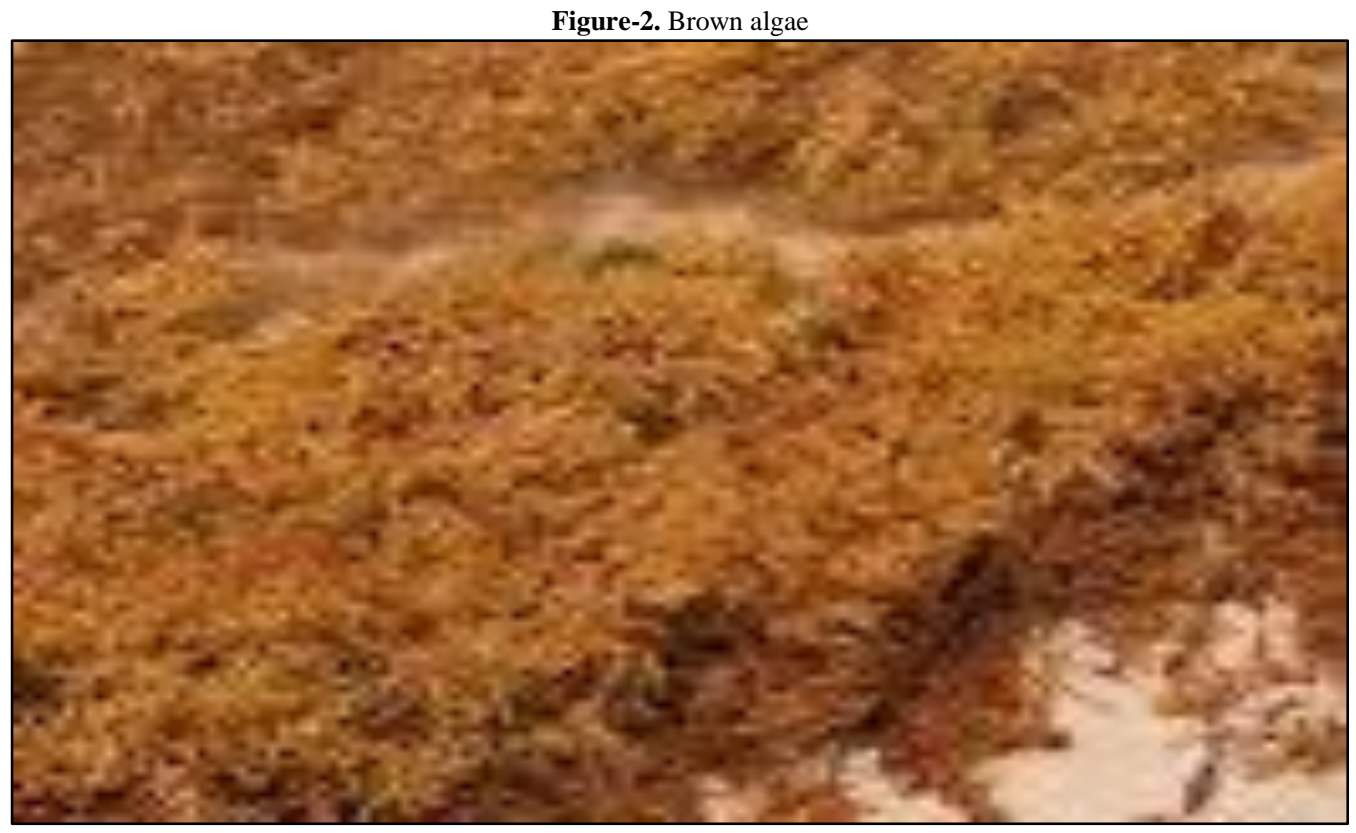

Brown algae comprising the class Phaeophyceae, contain alginic acid (alginate) in their cell walls and it may reach $60 \mathrm{~m}$ (200 ft.) in length, which is used as an industrial thickening agent in food [10].Its film forming and binding ability makes it suitable for the use of packaging material and for the use in biomedical application [11, 12].

\section{Alginate}

\subsection{Source and Properties}

Alginic acid and its salts $[\mathrm{Ca}, \mathrm{Mg}, \mathrm{Na} \& \mathrm{~K}]$ are abundantly present in brown algae that is quite abundant in nature and occurs both as a structural component in marine algae \& making up as much as $40 \%$ of the dry weight $[13,14]$. Alginates were discovered by a British Pharmacist, E.C.C. Stanford; commercial production started in 1929 [15]. Annual production of alginates in the world is about 30,000 tones; $30 \%$ of this is utilized by the food industry while the rest is used in industrial, dental, pharmaceutical industry [16, 17]. Alginates are linear, unbranched copolymers composed of monomers of $\beta$-D Mannuronic acid (M) and $\alpha-1$ guluronic acid(G) residues joined together by [1-4] glycoside linkages. Depending on seaweed source, extraction and harvest time are arranged in an asymmetrical pattern of varying proportions of GG, MG and MM blocks [18]. Alginate that is commercially 
available is typically extracted from brown algae (Phaeophyceae), including Laminaria japonica, Laminaria hyperborea, Macrocystis pyrifera, Ecklonia maxima, Laminaria digitata and Ascophyllum nodosum and Lessonia nigrescens especially by aqueous alkali solutions treatment, typically with $\mathrm{NaOH}[19,20]$. The extract is then filtered and purified in order to produce water-soluble sodium alginate powder [21].

Figure-3. Sodium alginate extraction procedure [22]

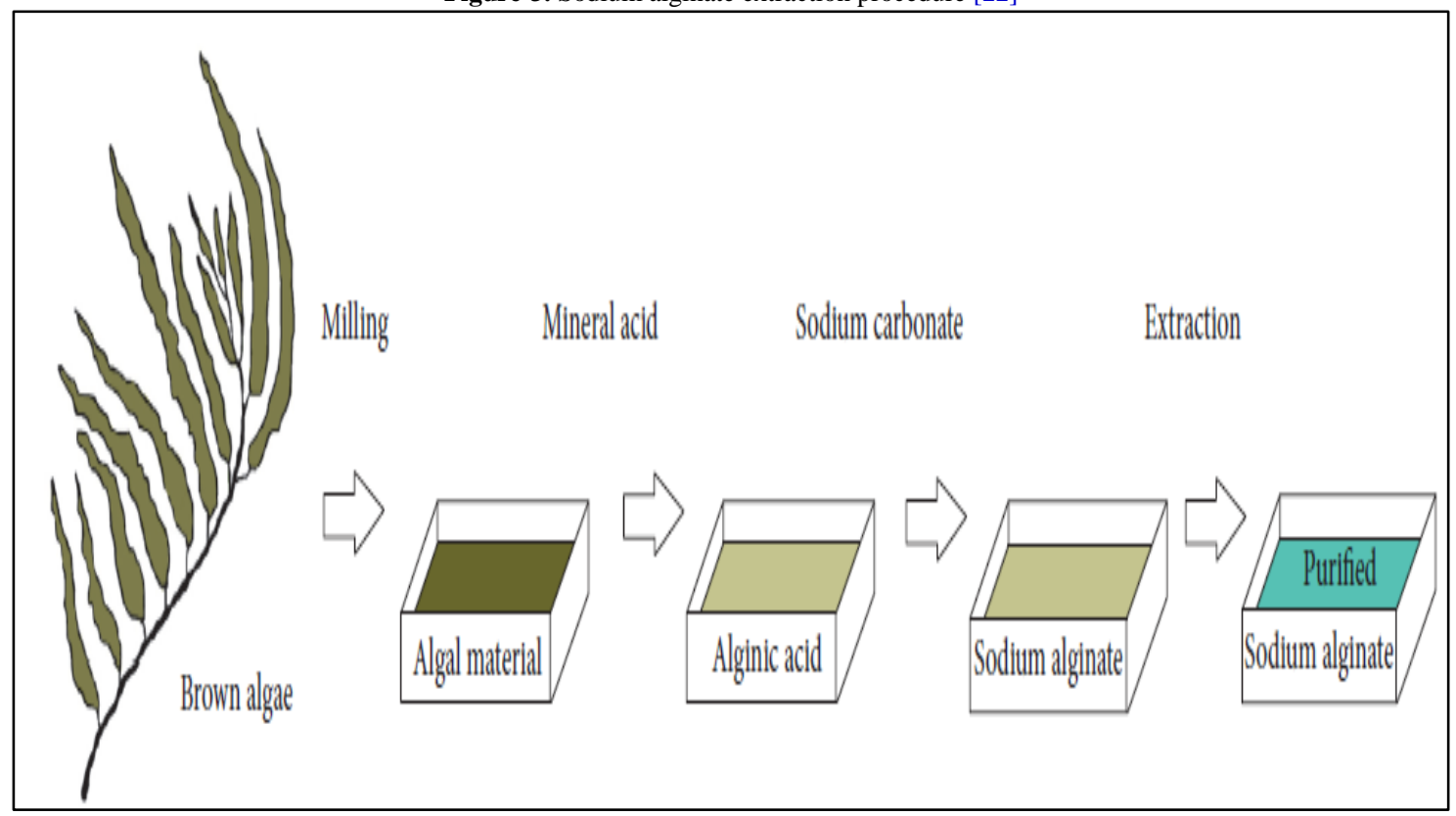

Sodium alginates is soluble in cold water, forming viscous, colloidal solution but insoluble in alcohol, hydro alcoholic solutions ,organic solvents viz. ether, and in acids .Calcium alginate, is however, practically insoluble in water and organic solvents [23]. If $\mathrm{Ca}^{2+}$ ions can be removed degradation of a $\mathrm{Ca}^{2+}$ cross-linked alginate gel can happen [24]. Biocompatibility, biodegradability, non-toxicity and immunogenicity properties of this polymer materials has made it versatile for usage in food, packaging, biomedical application, paper industry, textiles and medical textiles [25]. They are appealing film-forming compounds because of its thickening, stabilizing, suspending, gel-producing functional properties [26].

\subsection{Applications}

Alginates are widely used as additives in jams, jellies, ice-creams etc. as it is capable of stabilizing, viscosifying, emulsifying solutions [27]. Alginate film is being used as beverage additive for stabilization and to prevent moisture loss of meat during storage [28, 29]. Fayaz et Al showed incorporation of silver nanoparticles in alginate film for vegetable and fruit preservation [30]. ALG have been investigated as taste masking agents .Calcium complexed alginate mixed with starch was proposed to get high water retention in paper coating and to improve crumpling and resistance of paper [31]. In textile industry, alginate is favorably being used as thickener for the paste that contain dye [32]. In biomedical field, alginate are considered as favorable candidates in chubbiness and type 2 diabetes treatment as they are inhibitor of glucose transporters and glucose intestinal absorption rate [33]. Cheap, hydrophilic, non-staining, pleasant odor and taste and effective use in the presence of saliva, self-life of alginate, makes it suitable for application in dental impression materials [34]. Study revealed that alginate combined with chitosan and Ag (silver) nano-particles can form excellent antibacterial wound dressing as they are breathable, non-allergic , bacteriostatic, anti-viral, fungistatic, non-toxic, high absorbent, biocompatible and have good mechanical properties [35]. Modern dressings from alginate i.e. Algicell ${ }^{\mathrm{TM}}$ (Derma Sciences) AlgiSite $\mathrm{M}^{\mathrm{TM}}$ (Smith \& Nephew), Comfeel Plus $^{\mathrm{TM}}$ (Coloplast), Kaltostat ${ }^{\mathrm{TM}}$ (ConvaTec), provide a moist wound environment and facilitate wound healing [21]. Alginic acid fiber is easy to make to enhance antimicrobial properties and it can be prepared through wet spinning process with good tensile strength and good hand feeling. Alginate fibre complexed with calcium show good flame retardant characteristics [25]. Sodium alginate oligosaccharides have also been reported to lower blood pressure Amphiphilic gel beads have also prepared to modulate the release of hydrophobic drugs for the treatment of breast cancer. Another study showed that blends of alginate, chitin/chitosan, and fucoidan gels can provide a moist healing environment in case of wound dressing material [36]. Alginate gels have been widely explored over the past several decades for their potential approach in tissue engineering, tissue regeneration, cell adhesion and cell migration behavior [37, 38]. Alginate polymers have been extensively studied for prolonged or controlled release drug delivery systems [39]. AlgiMatrix prepared of pharmaceutical-grade alginate have been able to entrap cell into the porous structure in an anti-cancer based study [40]. After the pore is filled with alginate solution, formation of in-situ hydrogel enables fast cell immobilization [41]. It is clearly inferring that owing to unique properties, the utilization \& new usage of alginate is swelling day by day. 


\section{Agar}

\subsection{Source and Properties}

Agar-agar, is a Malayan word obtained by the discovered by Minoya Tarazaemon in 1658 in Japan, from marine algae Gelidium corneum and made its chemical analysis. It is a phycocolloid extracted from the cell wall of a group of red algae (Rhodophyceae) including Gelidium and Gracilaria [42]. Gelidium is the preferred source for agar production. Agar is formed by a mixture of two polysaccharides named agarose and agaropectin with agarose making up about $70 \%$ of the mixture [43]. It is proved that agarose is responsible for gelling properties whereas agaropectin is responsible for thickening properties [44]. Being a sulfuric acid ester of a linear galactan, agar is soluble in hot water but insoluble in cold water. Agar refers to neutral polysaccharide with repeated D-galactose and 3,6-anhydro-L-galactose units joined by $\beta-1,3-$ and $\alpha$-1,4-glycosidic bonds, respectively [45] with possible occurrence of sulphate, methoxyl, and/or pyruvate substituents at various positions in the polysaccharide chain [46]. Agar from Gelidium has melting \& gelling temperature between $80-90^{\circ} \mathrm{C}$ and $28-31^{\circ} \mathrm{C}$ whereas agar extracted from Gracilaria has gelling and melting temperatures between $29-42^{\circ} \mathrm{C}$ and $76-92^{\circ} \mathrm{C}$ respectively Agar in red algal cell wall is believed to provide resistance to pathogens [47] Agar

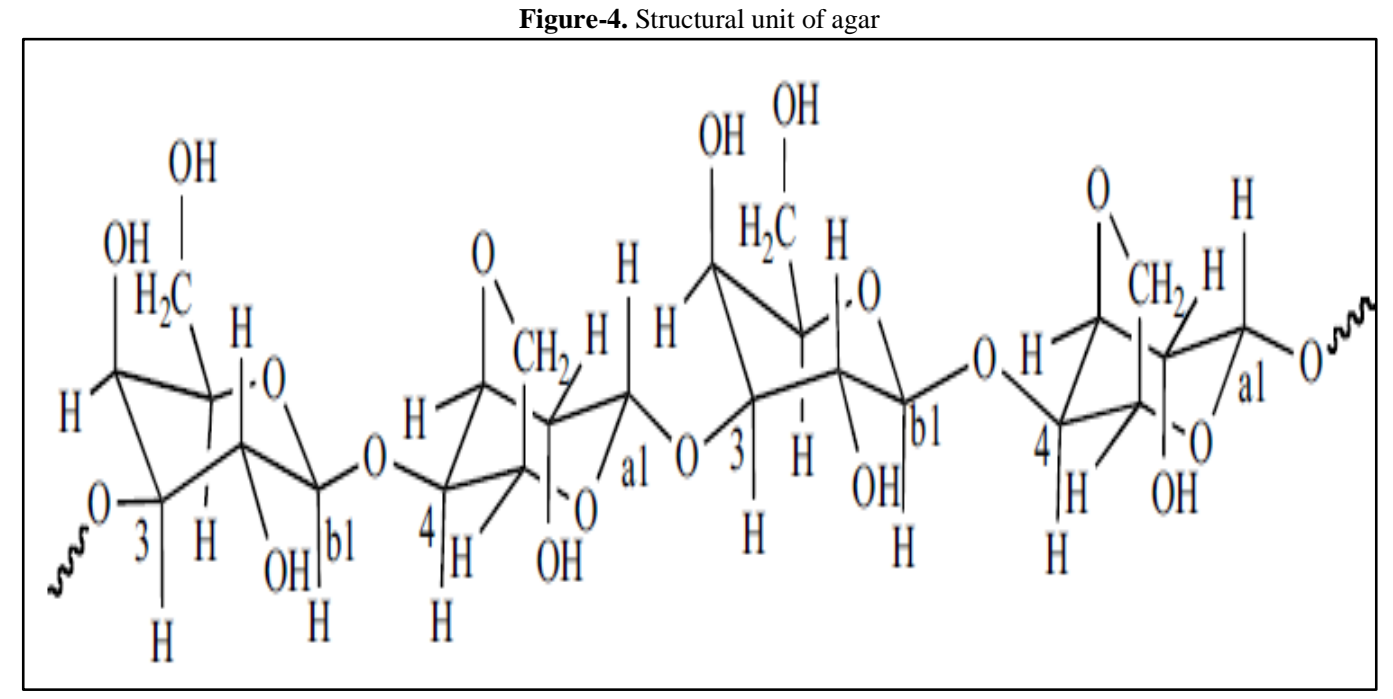

has great gelling power in an aqueous environment which is stronger than those of any other gel-forming agent [48]. Agar gives gels without flavor and does not need to add reagents to produce gelation such as $\mathrm{K}$ (necessary for carrageenans) or $\mathrm{Ca}$ (necessary for alginates). At $1.5 \%$ concentrated solution agar form gels between $32-43^{\circ} \mathrm{C}$ and does not melt below $85^{\circ} \mathrm{C}$. This is a unique property of agar known as hysteresis property.

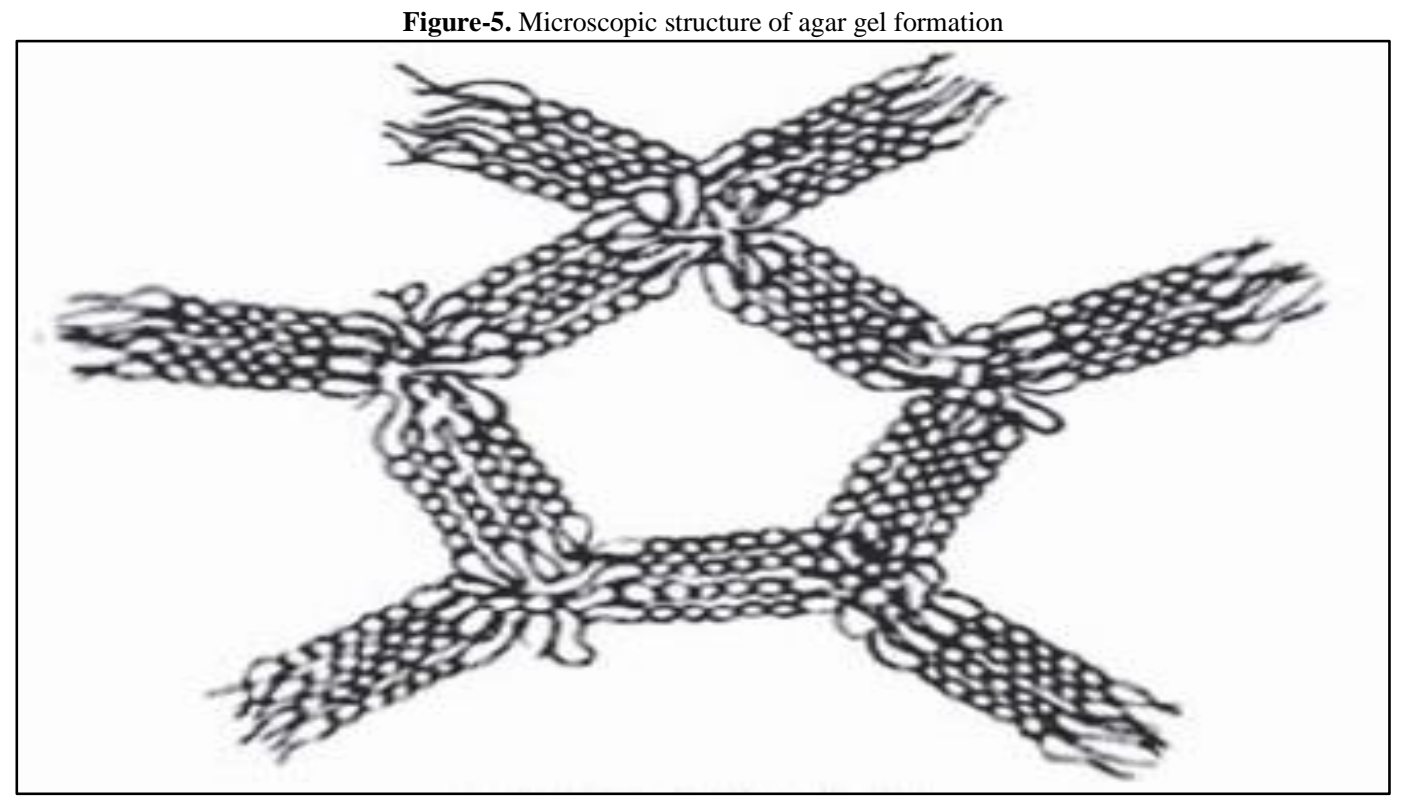

\subsection{Applications}

Thanking to its biodegradable nature, agar is intensively being used in food and beverages, pharmaceutical, paper, textile and biotechnology industry. In food industry, it is used as additive rather than as nutrient and as a covering agent to prevent dehydration while baking the food material [49]. Moreover, $80 \%$ of the globally produced agar is used as gelling, thickening, stabilizing and viscosity controlling agent for jellies, candies and jams, pudding, 
stabilizers for canned food, dessert, ice-cream, sauces [50, 51]. In addition to food applications, about $10 \%$ of all agar is currently being used as clarifying agent in brewing, binder for deserts, textile and paper making, clarifier, for wine making, aids in making ultra-thin separating film and in paper sizing fabrics [52]. One study showed the usage of agar-based metallic nanoparticles ( $\mathrm{Fe}, \mathrm{Cu}, \mathrm{Pd}$ etc.) to remove cationic dyes that can be applied in degradation of noxious dyes from industrial textile wastewater [53]. Jeevan et al showed that crystallized nanocellulose blended with agar can be used as a reinforcing agent for the preparation of bio-nanocomposites that have high potential as biodegradable food packaging materials [54]. Another researcher has experimented that in food packaging application, the addition of NCC improves film mechanical, thermal \& water vapor barrier properties though film transparency decreased [55]. Agar has given the research a pool of opportunities to discover new compound and its therapeutics value. Its high gel strength at low concentrations, low viscosity in solution, high transparency in solution, thermo-reversible gel and sharp melting/setting temperatures makes it suitable for usage in biomedical treatment [56]. It can also purify human body as it has binding ability to heavy metals, carcinogens and pesticides and can remove from our body through its cell wall [57]. Agar is also widely used as medium for antibody clone typing of various bacterial virulence antigens [58]. Agar usages in nano engineering have been recently developed for various applications i.e. synthesis of silver nano-particles using agar, with bactericidal effect, may find applications in wound dressing [59]. Meanwhile, impression materials in dentistry, intestinal regulator, excipient in pills, to make salt bridges and gel plugs for use in electrochemistry ,as a substrate for precipitin reactions in immunology [60]. Today the invention of new agar-based formulas are widely used as supporting matrices in animal cell culture, drug delivery, tissue engineering ,immobilizing agent for enzymes and microorganisms in various biochemical and fermentation industries.

\section{Carrageenan}

\subsection{Source and Properties}

Carrageenan is a naturally occurring anionic sulfated linear polysaccharide extracted from red algae specifically from the Rhodophyceae family, consisting of linear-sulfated polysaccharides of D-galactose and 3,6-anhydro-Dgalactose (3,6-AG) [61]. This specific type of seaweed is common in the Atlantic Ocean near Europe, Britain and North America. The sulfated polysaccharides are further extracted using dilute alkaline solution. Using of alkali brings chemical changes which leads to increased gel strength in the final product. Carrageenan was discovered by British pharmacist Stanford in year 1862 [3, 49]. It is a complex mixture of five distinct polymers designated as $l^{-}, \kappa-$ ,$\lambda-, \mu$-, and $v$-carrageenan [62]. Among those, three major types i.e. lambda $(\lambda)$, kappa $(\kappa)$, and iota have sulfate contents of $41 \%, 33 \%$, and $20 \%$ respectively. Classification of carrageenan was made based on its solubility in $\mathrm{KCl}$. Compared to $\lambda$ - and $l$-carrageenan; $\kappa$-carrageenan membranes reveal better mechanical properties [63]. As carrageenan possess different types and compositions, it is most difficult to depict its characteristics [64]. It may lead to whole loss of functionality rapidly at high temperatures and low $\mathrm{pH}$ [65] .Carrageenan has a unique property to form a variety of gel textures at room temp:

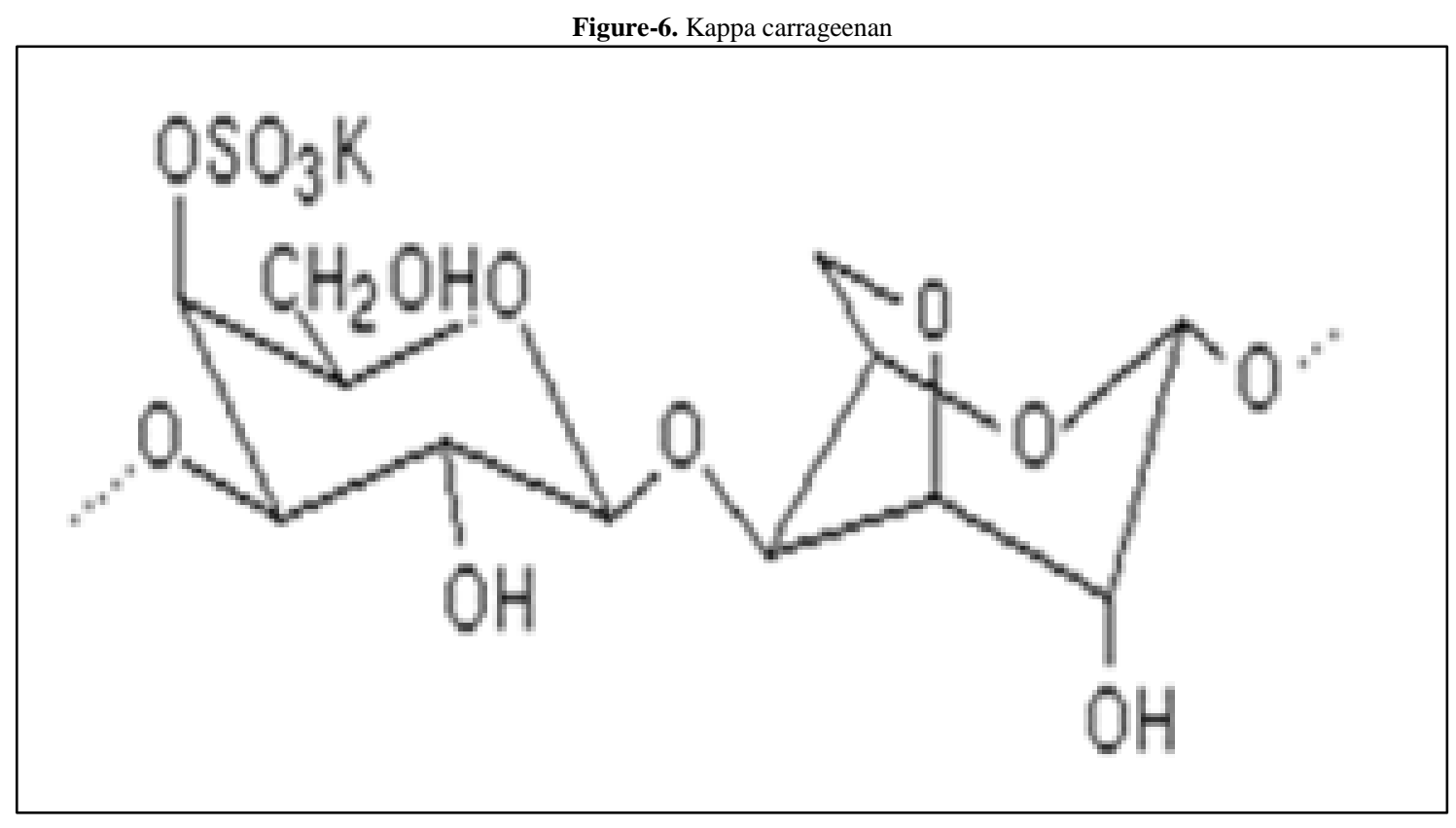




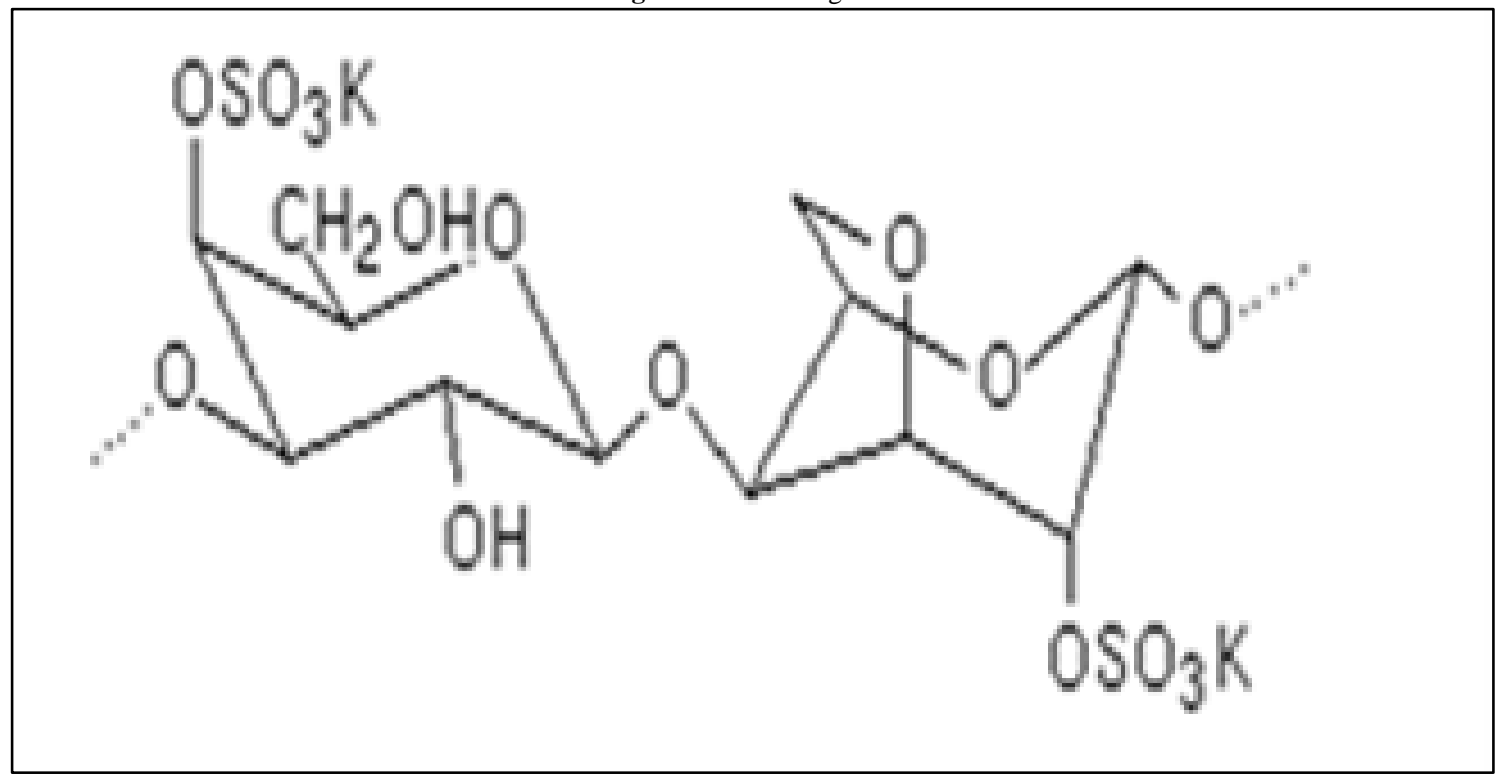

Figure-8. Lambda carrageenan

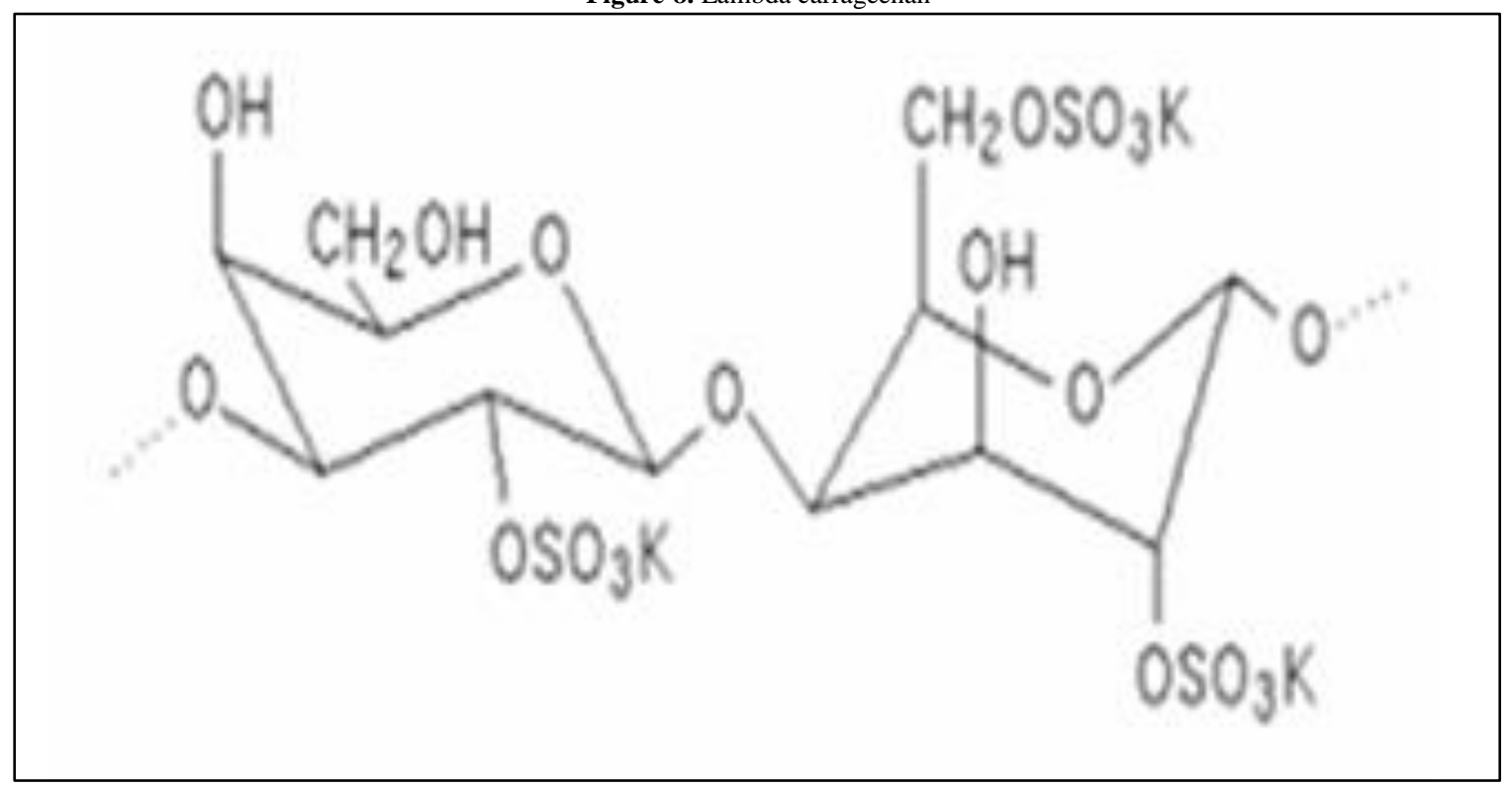

rigid or elastic, tough or tender, heat stable or thermally reversible, clear or turbid, low or high melting/gelling temperatures [66]. Kappa and iota-carrageenan can form gel through crosslinking in the presence of potassium or calcium ions, so it has great potential as a gel-forming material [26]. Iota-carrageenan produces softer, elastic; kappa-carrageenan forms rigid and brittle gels and lambda-carrageenan can’t create gel formation [67].

\subsection{Application}

Research on carrageenan is increasing steadily from the last decade. In order to meet the new renewable resources for the production of edible and biodegradable material, carrageenan can be used as an interesting alternative to produce edible films and coatings, food and beverages, biopackaging and medicine for biomedical application [68]. Among these different forms of carrageenans, kappa carrageenan is the one most commonly used in industrial applications. Semi refined carrageenan (SRC) for film packaging applications can be produced at a significantly lower cost due to the fewer number of processing steps required in its production. This opaque or colored packaging is widely used in food containers, trays, cups, wraps, and other packaging designed to preserve light- or UV-sensitive products. But pure carrageenan films limit its use for food packaging due to its brittle behavior [69]. Plasticizers like glycerol, non-volatile polyol are therefore typically added to the formulations in to improve their flexibility. For the manufacture of edible film carrageenan obtained from seaweed is being used as one of the cheapest raw materials. Saiful et al. prepared edible film from carrageenan that has been applied for slice apple packaging [70]. The optimized edible films structure was obtained with the carrageenan and palm oil as plasticizer which can maintain vitamin C of 99,853\%. Brody and colleagues have also reviewed commercial antimicrobial food packaging materials and structures and their applications [71]. Another promising emerging technology is to apply biopolymer coating i.e. carrageenan-based coating as antimicrobial agent carriers. Cha et al. studied the synergistic effect of antimicrobials and chelating agent (EDTA) in $\kappa$-carrageenan-based biopolymer films which showed inhibitory effects against all microorganisms and pathogens [72]. It has been widely utilized in food industry as 
thickening, gelling, stabilizing agent in ice-cream, milk shakes, chocolate milk, processed meat, fruit juices, desserts, cream thickener, sauces, jam, and canned food etc. [73]. Carrageenan as protective barrier can also be used in the food industry in order to prevent the transfer of moisture, gases, flavors or lipids and to maintain food quality and food product shelf-life [74]. If coating with carrageenan is chosen, a controlled respiratory exchange can be established and thus the preservation of fresh fruits and vegetables can be prolonged [75]. Besides nanocomposites with nanoclays or with cellulose nano-whiskers are able to block the light against UV-visible, which is of interest in packaging and membrane applications [76]. The application of carrageenan is also gaining attention in industry as thickeners for tooth paste, cosmetic, lotion, ceramic coatings etc. Recently, the utilization of carrageenan is increasing in other areas, such as drug delivery, tissue engineering, dengue and herpes virus, beads for controlled released system, to reduce cholesterols and lipids levels, suspending agents in antacid, eye drops, suppositories and biosensor applications [77, 78]. Gan and Feng et al. discovered a new injectable biomaterial carrageenan/nanohydroxyapatite/collagen for bone surgery [79]. Moreover, carrageenan has antitumor and immunomodulation activities, antiviral activity, antioxidant activity, anticoagulant and antithrombotic activities for which it is massively used as drug delivery tool $[80,81]$.

\section{Conclusion}

In this review, seaweed based polymeric film has demonstrated numerous advantageous, which is of great potential to food, packaging, medical and high end productions identified with natural insurance and the support of physical wellbeing. The emergence of natural polymers about few decades ago reduced the need for synthetic polymer production at a low cost, thereby producing a positive effect both environmentally and economically by producing highly sustainable, functional and cost-effective products. The promising research trend undertaken in this direction will hopefully lead biodegradable polymers to domain their fields with more simulated properties. In future, seaweed and its derivative blends will be more innovative and multifunctional that can be researched for further development and application.

\section{References}

[1] Smith, G. M., 1944. Marine Algae of the Monterey Peninsula. 2nd ed. California: Stanford University.

[2] Guiry, M. D., 2000-2019. "The Seaweed Site: Information on marine algae."

[3] Abdul Khalil, H. P. S., Tye1, Y. Y., Saurabh, C. K., Leh, C. P., Lai, T. K., and Chong, E. W. N., 2017. "Biodegradable polymer films from seaweed polysaccharides: A review on cellulose as a reinforcement material." Express Polymer Letters, vol. 11, pp. 244-265.

[4] García-Casal, M. N., Pereira, A. C., Leets, I., Ramírez, J., and Quiroga, M. F., 2007. "High iron content and bioavailability in humans from four species of marine algae." Journal of Nutrition, vol. 137, pp. 26912695.

[5] Huebsch, N. and Mooney, D. J., 2009. "Inspiration and application in the evolution of biomaterials." Nature, vol. 462, pp. 426-432.

[6] Ratner, B. D. and Bryant, S. J., 2004. "Biomaterials: where we have been and where we are going?" Ann. Rev. Biomed. Eng., vol. 6, pp. 41-75.

[7] Garcia-Vaquero, M. and Hayes, M., 2016. "Red and green macroalgae for fish and animal feed and human functional food development." Food Reviews International, vol. 32, pp. 15-45.

[8] Abbott, I. A. and Hollenberg, G. J., 1976. Marine Algae of California. California: Stanford University Press.

[9] Prescott, G. W., 1968. The Algae: A Review. Boston: Houghton Mifflin Company. pp. 207-231, 371-372.

[10] Hoek, C., den Hoeck, H. V., Mann, D., and Jahns, H. M., 1995. Algae: An introduction to phycology. Cambridge University Press.

[11] Alginic acid. Available: www.fao.org

[12] Wynne, M. J., 1981. "The Biology of seaweeds."

[13] Gitzendanner, M. A., Soltis, P. S., Wong, G. K., Ruhfel, B. R., and Soltis, D. E., 2018. "Plastid phylogenomic analysis of green plants: A billion years of evolutionary history." American Journal of Botany, vol. 105, pp. 291-301.

[14] Hadas, H. and Simcha, S., 2017. "Structural characterization of sodium alginate and calcium alginate." Biomacromolecules, vol. 17, p. 2160-2167.

[15] Nikhil, K. S., Seema, P., and Antesh, J. A., 2009. "Bhattcharya, Sodium alginate: The wonder polymer for controlled drug delivery." Journal of Pharmacy Research, vol. 2, pp. 1191-1199.

[16] Ertesvag, H. and Valla, S., 1998. "Biosynthesis and applications of alginates." Polym. Degrad. and Stability, vol. 59, pp. 85-91.

[17] Johnson, F. A., Craig, D. Q. M., and Mercer, A. D., 1997. "Characterization of the block structure and molecular weight of sodium alginates." J. Pharm. Pharmacol., vol. 49, pp. 639-643.

[18] Rhein-Knudsen, N., Ale, M. T., and Meyer, A. S., 2015. "Seaweed hydrocolloid production: An update on enzyme assisted extraction and modification technologies." Marine Drugs, vol. 13, pp. 3340-3359.

[19] Clark, D. E. and Green, H. C., 1936. "Alginic acid and process of making same. US Patent. 2036922."

[20] Smidsrod, O. and Skjak-Bræk, G., 1990. "Alginate as immobilization matrix for cells." Trend Biotechnol., vol. 8, pp. 71-78. 
[21] Kuen, Y. L. and David, J., 2012. "Mooney, Alginate, properties and biomedical applications." Prog. Polym. Sci., vol. 37, pp. 106-126.

[22] Marta, S., Agata, P., and Emilia, S., 2016. "Alginate: Current Use and Future Perspectives in Pharmaceutical and Biomedical Applications, IJPS, ID 7697031." p. 17.

[23] Hilpa, A., Agrawal, S. S., and Ray, A. R., 2003. "Controlled delivery of drugs from alginate matrix." Journal of Macromolecular science part CPolymer Reviews, vol. 43, pp. 187-221.

[24] Gombotz, W. R. and Wee, S. F., 1998. "Protein release from alginate matrices." Adv. Drug Deliv. Rev., vol. 31, pp. 267-285.

[25] Marguerite Rinaudo, 2014. "Biomaterials based on a natural polysaccharide, Alginate." TIP Revista Especializada en Ciencias Químico-Biológicas, vol. 17, pp. 92-96.

[26] Tavassoli-Kafrani, E., Shekarchizadeh, H., and Masoudpour-Behabadi, M., 2016. "Development of edible films and coatings from alginates and carrageenans." Carbohydr. Polym., vol. 137, pp. 360-374.

[27] Sabra, W. and Deckwer, W. D., 2005. "Alginate - A polysaccharide of industrial interest and diverse biological functions. In Polysacharides. Structural diversity and functional versatility." pp. 515-533.

[28] Jackson, G., Roberts, R. T., and Wainwright, T., 2013. "Mechanism of Beer Foam Stabilization by Propylene Glycol Alginate." J. inst. Brew., vol. 86, pp. 34-37.

[29] Mastromatteo, M., Conte, A., and Del, N. M. A., 2013. "Combined effect of active coating and MAP to prolong the shelf life of minimally processed kiwifruit." J. Dairy Sci., vol. 97, pp. 36-45.

[30] Fayaz, A., Balaji, K., Girilal, M., and Kalaichelvan, P. T., 2009. "Mycobased synthesis of silver nanoparticles and their incorporation into sodium alginate films for vegetable and fruit preservation." Journal of Agricultural and Food Chemistry, vol. 57, pp. 6246-52.

[31] Joyce, M. and Gilbert, S. A., 1996. "Effect of $\mathrm{Ca}+2$ on the water retention of alginate in paper coatings." Journal of Pulp and Paper Science, vol. 22, pp. J126-J130.

[32] Arumugam, N., 2016. "Anandakumar shanmugam and Aslambasha Zackaria, Mini review on Alginate: Scope and Future perspectives." J. Algal Biomass Utln., vol. 7, pp. 45- 55.

[33] Yavorska, N., 2012. "Sodium alginate, A potential tool for weight management: effect on subjective appetite, food intake, and glycemic and insulin regulation." Journal of Undergraduate Life Sciences, vol. 6, pp. 66-69.

[34] Madhavan, S., 2015. "Abirami: A review on hydrocolloids-agar and alginate." Journal of Pharmaceutical Sciences and Research, vol. 7, pp. 704-707.

[35] Suzuki, K., Suzuki, Y., Tanihara, M., Hashimoto, T., and Endo, K., 2000. "Reconstruction of rat peripheral nerve gap without sutures using freeze dried alginate gel." Journal of Biomedical Materials Research, vol. 49, pp. 528-533.

[36] Murakami, K., Aoki, H., Nakamura, S., Nakamura, S., Takikawa, M., Hanzawa, M., Kishimoto, S., Hattori, H., and Tanaka, Y., 2010. "Hydrogel blends of chitin/chitosan, fucoidan and alginate as healing-impaired wound dressings." Biomaterials, vol. 31, pp. 83-90.

[37] Andersen, T., Markussen, C., and Dornish, M., 2014. "In situ gelation for cell immobilization and culture in alginate foam scaffolds." Tissue Engineering Part A, vol. 20, pp. 600-610.

[38] Xu, X., Wu, X., and Wang, Q., 2014. "Immunomodulatory effects of alginate oligosaccharides on murine macrophage RAW264.7 cells and their structure-activity relationships." Journal of Agricultural and Food Chemistry, vol. 62, pp. 3168-3176.

[39] Witvrouw, M. and De Clercq, E., 1997. "Sulfated polysaccharides extracted from sea algae as potential antiviral drugs." General Pharmacology, vol. 29, pp. 497-511.

[40] Godugu, C., Patel, A. R., Desai, U., Andey, T., Sams, A., and Singh, M., 2013. "AlgiMatrix based 3D cell culture system as an in-vitro tumor model for anticancer studies." PLOS ONE, vol. 8, p. e53708.

[41] Andersen, T., Auk-Emblem, P., and Dornish, M., 2015. "3D cell culture in alginate hydrogels." Microarrays, vol. 4, pp. 133-161.

[42] Xiao, T. F. and Sang, M. K., 2010. "Agarase: Review of Major Sources, Categories, Purification Method, Enzyme Characteristics and Applications." Mar. Drugs, vol. 8, pp. 200-218.

[43] Araki, C. H., 1937. "Acetylation of agar like substance of Gelidium amansii." J. Chem. Soc., vol. 58, pp. 1338-1350.

[44] Armisén, R. and Galatas, F., 2009. Agar. Handbook of hydrocolloids eds. Phillips G., Williams P. Boca Raton: CRC Press. pp. 82-107.

[45] Lee, W.-K., Lim, Y.-Y., Leow, A. T.-C., Namasivayam, P., Abdullah, J. O., and Ho, C.-L., 2017. "Biosynthesis of agar in red seaweeds: A review." Carbohydrate Polymers, vol. S0144-8617, pp. 30089-9.

[46] Rees, D. A., 1969. "Structure, conformation, and mechanism in the formation of polysaccharide gels and networks." Adv. Carbohydr. Chem. Biochem., vol. 24, pp. 267-332.

[47] Lahaye, M. and Rochas, C., 1991. "Chemical structure and physicochemical properties of agar." Hydrobiologia, vol. 221, pp. 137-148.

[48] Capillo, G., Sanfilippo, M., Aliko, V., and Spanò, N., 2017. "Gracilaria gracilis, Source of Agar: A Short Review." Current Organic Chemistry, vol. 21, pp. 380-386.

[49] Pereira, L., 2011. A review of the nutrient composition of selected edible seaweeds in Seaweed: Ecology, nutrient composition and medicinal uses' ed.: Pomin V. H. New York: Nova Science Publishers. pp. 15-47.

[50] Avvari, S. K. S. and Nagarjuna, N., 2011. "Venkata kullai settee, A comprehensive review on marine algae and their multidisciplinary activities." IJAPBS, vol. 1, pp. 44-50. 
[51] Rajasulochana, P. and Preethy, V., 2015. "Biotechnological applications of marine red algae." Journal of Chemical and Pharmaceutical Research, vol. 7, pp. 477-481.

[52] Cardozo, K. H. M., Guaratini, T., Barros, M. P., Falcão, V. R., Tonon, A. P., and Lopes, N. P., 2007. "Metabolites from algae with economical impact." Comparative Biochemistry and Physiology Part C, Toxicology and Pharmacology, vol. 14, pp. 60-78.

[53] Patra, S., Roy, E., Madhuri, R., and Sharma, P. K., 2015. "Agar based bimetallic nanoparticles as highperformance renewable adsorbent for removal and degradation of cationic organic dyes." J. Ind. Eng. Chem., vol. 33, pp. 226-238.

[54] Jeevan, P. R. and Jong-Whan, R., 2014. "Characterization of bionanocomposite films prepared with agar and paper-mulberry pulp nanocellulose." Elsevier, Carbohydrate Polymers, vol. 110, pp. 480-488.

[55] Shankar, S. and Rhim, J. W., 2016. "Preparation of nanocellulose from micro-crystalline cellulose: The effect on the performance and properties of agar-based composite films." Carbohydrate Polymers, vol. 135, pp. 18-26.

[56] Agar-agar Review Sheet, 1995. "USDA Organic Materials Review."

[57] EnricaCaló, V. and Khutoryanskiy, V., 2015. "Biomedical applications of hydrogels: A review of patents and commercial products." European Polymer Journal, vol. 65, pp. 252-267.

[58] Sambrook, J., Fritsch, E. F., and Maniatis, T., 1989. Molecular cloning, A laboratory manual. 2nd ed. New York: Cold Spring Harbor Laboratory Press.

[59] Shukla, M. K., Singh, R. P., Reddy, C. R. K., and Jha, B., 2012. "Synthesis and characterization of agarbased silver nanoparticles and nanocomposite film with antibacterial applications." Bioresour. Technol., vol. 107, pp. 295-300.

[60] 2007. "Agar Archived, at the Wayback Machine. at 1sbu.ac.uk Water Structure and Science."

[61] Ana, R. V., Ferreira, V., Alves, D., and Isabel, M. C., 2016. "Polysaccharide-Based Membranes in Food Packaging Applications, Membranes."

[62] Nisperos-Carriedo, 1994. Edible coatings and films based on polysaccharides. In Edible coatings and films to improve food quality. Lancaster, PA.M.O: Technomic Publishing Co. Inc. pp. 305-335.

[63] Campos, C. A., Gerschenson, L. N., and Flores, S. K., 2011. "Development of edible films and coatings with antimicrobial activity." Food Bioprocess Technol., vol. 4, pp. 849-875.

[64] De Ruiter, G. A. and Rudolph, B., 1997. "Carrageenan biotechnology." Trends in Food Science and Technology, vol. 8, pp. 389-395.

[65] Necas, J. and Bartosikova, L., 2013. "Carrageenan: A review." Veterinarni Medicina, vol. 58, pp. $187-205$.

[66] Lui, Y., Schnaram, R., and Reily, W., 1997. "Evaluation of Carrageenan as Suppository Base." Pharm. Res., vol. 14, p. 41.

[67] Campo, V. L., Kawano, D. F., da Silva, D. B., and Carvalho, I., 2009. "Carrageenans: Biological properties, chemical modifications and structural analysis - A review." Carbohydrate Polymers, vol. 77, pp. 167-180.

[68] Dong, S. C. and Manjeet, S. C., 2004. "Biopolymer-based antimicrobial packaging: A review." Critical Reviews in Food Science and Nutrition, vol. 44, pp. 223-237.

[69] Bakti, B., Sedayu, M. J., and Cran, S. W. B., 2018. "Characterization of semi-refined carrageenan-based film for primary food packaging purposes." Journal of Polymers and the Environment, vol. 0924, p. 1255.

[70] Saiful, S. and Saleha, S., 2013. "Preparation and characterization edible film packaging from carrageenan." In The 3rd Annual International Conference Syiah Kuala University.

[71] Brody, A. L., Strupinsky, E. R., and Kline, L. R., 2001. Antimicrobial packaging. In Active packaging for food applications. Lancaster: Technomic Publishing Co. Inc. pp. 131-194.

[72] Cha, D. S., Choi, J. H., Chinnan, M. S., and Park, H. J., 2002. "Antimicrobial films based on Na-alginate and $\kappa$-carrageenan. Lebensm.-Wiss. u.-Technol." vol. 35, pp. 715-719.

[73] Prajapati, V. D., Maheriya, P. M., Jani, G. K., and Solanki, H. K., 2014. "Carrageenan: a natural seaweed polysaccharide and its applications." Carbohyd. Polym., vol. 105, pp. 97-112.

[74] Krochta, J. M. and De Mulder-Johnston, C., 1997. "Edible and biodegradable polymer films: Challenges and opportunities." Food Technology, vol. 51, pp. 61-74.

[75] Ayranci, E. and Tunc, S., 2003. "A method for the measurement of the oxygen permeability and the development of edible films to reduce the rate of oxidative reactions in fresh foods." Food Chemistry, vol. 80, pp. 423-431.

[76] Sanchez-Garcõ̂̂A, M. D., Hilliou, L., and LagaroÂn, J. M., 2010. "Nanobiocomposites of carrageenan, zein and mica of interest in food packaging and coating applications." Journal of Agricultural and Food Chemistry,

[77] Li, L., Ni, R., Shao, Y., and Mao, S., 2014. "Carrageenan and its applications in drug delivery." Carbohyd. Polym., vol. 103, pp. 1-11.

[78] Popa, E. G., Caridade, S. G., Mano, J. F., Reis, R. L., and Gomes, M. E., 2015. "Chondrogenic potential of injectable k-carrageenan hydrogel with encapsulated adipose stem cells for cartilage tissue engineering applications." J. Tissue Eng. Regen. Med., vol. 9, pp. 550-563.

[79] Gan, S. L. and Feng, Q. L., 2006. "Preparation and characterization of a new injectable bone substitutecarrageenan/nano-hydroxyapatite/collagen." Acta Academiae Medicinae Sinicae, vol. 28, pp. 710-713.

[80] Rocha, d. S. M. C., Marques, C. T., Dore, C. M. G., da Silva, F. R. F., Rocha, H. A. O., and Leite, E. L., 2007. "Antioxidant activities of sulfated polysaccharides from brown and red seaweeds." Journal of Applied Phycology, vol. 19, pp. 153-160. 
[81] Yuan, H., Song, J., Li, X., Li, N., and Dai, J., 2006. "Immunomodulation and antitumor activity of $\kappa-$ carrageenan oligosaccharides." Cancer Letters, vol. 243, pp. 228-234. 